\title{
Moving engagement "upstream"? Nanotechnologies and the Royal Society and Royal Academy of Engineering's inquiry
}

\author{
Tee Rogers-Hayden and Nick Pidgeon
}

In response to the impetus that is gathering in the UK for upstream public engagement, we analyze the impacts of the Royal Society and Royal Academy of Engineering report of 2004 on Nanoscience and Nanotechnologies: Opportunities and Uncertainties. The paper presents an analysis of 24 interviews with stakeholders to the nanotechnology debate. It uses these to discuss the inquiry process and the recommendations contained within the report, as well as to explore and critique the notion of "upstream." We find broad support for the inquiry, which was positioned by many stakeholders itself as upstream, primarily because of its broad framing and wide stakeholder involvement. A number of both explicit and implicit upstream elements are also contained within its recommendations. However, the interviews also suggest that the notion of upstream engagement is a contested concept with a range of associated dilemmas and tensions. In drawing out some of the promise and perils of moving public debate upstream, the paper concludes that there is a risk of merely replacing the perceived deficit in public understanding of science with a perceived deficit in public engagement with science.

\section{Introduction}

There is considerable emphasis today in the UK being placed upon stakeholder and public dialogue $^{1}$ in relation to science and technology issues. Such processes have in many respects overtaken attempts to promote increased public understanding of science and greater science literacy through more traditional science communication methods. However, a valid criticism of much public engagement ${ }^{2}$ is that it often only occurs after a controversial social or ethical question has arisen in relation to a new technology. And this may be only quite late in the research, development and application cycle. Under such circumstances public engagement may well, intentionally or unintentionally, serve only token purposes, especially so if the engagement comes too late to influence significant decisions or applications that are locked in by commercial or other constraints.

The notion of promoting engagement early for emerging technology has been gaining support, amongst not only civil society groups and the science policy communities (e.g. 
Wilsdon and Willis, 2004; Royal Society and Royal Academy of Engineering, 2004; Wilsdon et al., 2005; Macnaghten et al., 2005) but also, perhaps most significantly, some sectors of the UK government (HM Treasury et al., 2004). It involves consideration of a technology, and any potential social and ethical issues, before significant research and development decisions are made and become locked in. There are clearly benefits to enabling public engagement at such an early stage of any emerging technology's life cycle. Most important of these is the potential to debate and envision fundamental questions about the broad future trajectories that a particular technology might take, who will benefit or be harmed by those trajectories, and whether desired or unintended consequences will flow as a result. In addition, addressing issues at an early enough stage lends out the hope that key decisions can be influenced, while the polarization of opinion that often surrounds many controversial downstream issues is likely to be avoided. That, at least, is the theory.

The test case, and a contributing impetus, for moving dialogue upstream is that of nanotechnologies ${ }^{3}$ - the science and engineering of the very small. Nanotechnology involves the fabrication, manipulation and control of materials at the atomic level. The term itself derives from the unit of scale employed-with a nanometer being one billionth of a meter in length. Nanotechnology is of intense interest to scientists and engineers because at sizes below 100 $\mathrm{nm}$ the fundamental chemical or electrical properties of materials can change. Although some nanotechnology based products, as claimed by manufacturers, are already on the market (see Woodrow Wilson, 2006), their real potential is predicted to lie in a range of fundamental new advances over the next 10-50 years, in the domains of new materials, the environment, medicine and information technology. Alongside such hopes, nanotechnologies also raise a range of potentially difficult safety and ethical concerns, all of which are surrounded by considerable uncertainty (Mnyusiwalla et al., 2003; Wood and Jones, 2003; Pidgeon and RogersHayden, 2007).

In this paper, we investigate the case of nanotechnologies through research into the outcomes of the 2004 Royal Society and Royal Academy of Engineering (RS/RAEng) inquiry into the issue, using our analysis to also explore the notion of "upstream" public engagement.

When engagement is likely to be "upstream" is no simple matter to define in and of itself. One working definition of "upstream" engagement might be as follows:

Dialogue and deliberation amongst affected parties about a potentially controversial technological issue at an early stage of the research and development process and in advance of significant applications or social controversy.

The RS/RAEng report (2004) argued that most developments in nanotechnologies are still upstream in nature, in at least three senses: regarding investment decisions, impacts and public awareness. First, many significant decisions which will affect the future trajectory of nanotechnologies, particularly concerning research and development funding and infrastructure, have yet to be made. Second, many of the more radical impacts of nanotechnologies have yet to be envisioned, remain hypothetical, or will depend upon its convergence with other technologies. Third, in terms of public discourse, nanotechnologies have yet to gain any major place in public or popular media representations in Britain (an observation also paralleled by research in the US: see Macoubrie, 2006).

While the term upstream engagement has gained currency in the UK in regard to public deliberation, some of those who use it have noted the over-simplistic connotations it might invoke (see e.g. Wilsdon et al., 2005). Upstream is often used in contrast to "downstream" dialogue. The latter is typically held to occur too late in the technology development process to have significant influence. What these shorthand terms then tend to imply are overly simplistic, essentially linear trajectories for both technology and society. This renders largely 
invisible the processes of co-construction of technology with society which inevitably surround any emerging technological field (e.g. Bjiker et al., 1974). The model of technology-society relations implicit in upstream engagement is definitely not that of linear processes, or one that simply involves the publics ${ }^{4}$ either at the "top" of a fixed stream or at the "bottom." Rather, technology and society can and do develop in a multitude of ways which are both dynamic and mutually shaping (e.g. Rip et al., 1995). Upstream engagement can also be conceptualized as a response to Collingridge's (1992) dilemma, in that early on in the life of new technologies their impacts are often uncertain or concealed, whereas downstream (when impacts and downsides become much clearer) effective control opportunities may be few or limited. It is too early to state which nanotechnologies are likely to exhibit the properties that make them difficult to control (such as technological entrenchment/inflexibility, long lead times, and large scale), and many most likely will not. However, the theory at least is that by bringing a wide set of perspectives to bear at an early stage, this will suggest areas that might prove particularly problematic to control (Pidgeon, 1988).

Our analysis here of the notion of upstream public engagement suggests that the concept is indeed an important innovation, and one that appears to reflect a genuine moment of change currently occurring in the relationship between science and wider society, particularly within the UK. However, this analysis also suggests that the meaning of "upstream"- - while itself a deceptively simple idea-is in reality a contested matter in both conceptual and practical terms, containing a number of significant tensions and dilemmas of its own. In the final part of the paper we therefore attempt to draw out some of the promises and perils of moving debate "upstream."

\section{Policy context in the UK and the RS/RAEng inquiry}

When discussing the way in which the call for upstream public engagement has arisen at this moment in time, and in the UK in particular, it is important to take account of the ways in which UK science policy had been impacted by a recent history of controversy concerning science, technology and risk. Above all, two issues have dominated the public policy agenda and thinking. The Bovine Spongiform Encephalopathy (BSE or "mad cow") crisis, as well as the controversy over genetically modified (GM) crops, both occurring in the mid-to-late 1990s, marked a turning point in the way UK science policy was viewed. Both the Phillips (2000) inquiry into the causes of BSE and a wider House of Lords Science and Technology Committee (2000) report on Science and Society, argued that there existed a crisis of trust in UK science policy-making. ${ }^{5}$ A contributory factor was assumed to be a failure of the traditional one-way "deficit model" of science communication, as implied in the earlier Bodmer report (Royal Society, 1985) on science communication. In response, both reports stressed the importance of openness in government and the science community as a precondition to reestablishing credibility and trust in risk management and policy. The Lords report also highlighted a need to broaden the base of public consultation and dialogue on controversial science policy issues (see also POST, 2001). The implication was that we need to move beyond traditional public understanding of science efforts if we are to resolve some of the most contested issues within contemporary science policy.

These policy developments, in the way the relationship between science and society is conceptualized, must be seen within the context of changes in the governance of UK science more generally. This reflects, in particular, a change from what Hagendijk and Irwin (2006) categorize as "discretionary governance" to a more nuanced and fragmented approach, including that of "deliberative governance." Discretionary governance takes place with very little interaction with the public, relying almost entirely on technical and other forms of expert advice and the 
UK has, in the past, generally organized science policy in this discretionary mode. According to Hagendijk and Irwin, UK science policy has recently moved to a mixed-model incorporating a range of forms of governance, including deliberative governance in which organized public involvement responds to and in turn informs the political agenda for science.

While major dialogue and engagement processes have been used extensively in some other European nations such as Denmark, the Netherlands or Switzerland (see e.g. Renn et al., 1995; Joss, 1998), they have been less common in the UK. Consensus conferences had occurred in 1994 for plant biotechnology (POST, 1995) and in 1999 for radioactive waste management (UKCEED, 1999). The intense controversy over GM agriculture at the end of the 1990s also led to a further major public engagement exercise on biotechnology in 2003, the GM Nation? debate. This was an important experiment in multi-stage stakeholder engagement, and yet failed to fully meet its objectives, in part because of organizational, financial and political constraints (Horlick-Jones et al., 2007), but also because many of the participants in the open activities in the debate held firmly established positions prior to entering into the exercise (see Pidgeon et al., 2005).

Against this background of intense controversy, a greater willingness to experiment with engagement processes in the UK, and a concern that nanotechnologies might suffer the same fate as GM food had earlier in the UK, the government approached the Royal Society and Royal Academy of Engineering to undertake its inquiry. Its remit was to "identify what health and safety, environmental, ethical and societal implications or uncertainties may arise from the use of the technologies, both current and future" (RS/RAEng, 2004: vii). The year-long process was conducted by a working group and secretariat on behalf of the two academies, and its report Nanoscience and Nanotechnologies: Opportunities and Uncertainties was subsequently published in July 2004. The government responded to this with its own Response to the Royal Society and Royal Academy of Engineering Report: Nanoscience and Nanotechnologies: Opportunities and Uncertainties in early 2005.

The RS/RAEng working group sought both broad stakeholder and general public involvement. The composition of the independent working group included not only Fellows of both academies, drawn from the nanoscience and engineering communities, but also perspectives from social science, ethics, consumer protection and the environment. ${ }^{6}$ This broad stakeholder involvement carried through into the inquiry process itself. The two academies issued a call for written evidence, which was followed by oral evidence sessions and workshops. This included sessions for industry representatives, regulators, public engagement specialists, civil society representatives, scientists and engineers, together with specialist workshops on environmental impacts and implications and on the health impacts of nanotechnologies. The collection of evidence therefore created a significant additional resource on nanotechnologies, with the evidence being placed on a website and included in the final report as a compact disk (RS/RAEng, 2004).

Unusually, for a science policy document of the two academies, the inquiry group also sought views of "ordinary members of the public" through both survey ${ }^{7}$ and qualitative workshop methodologies. ${ }^{8}$ It was expected, and found, that general public awareness of nanotechnologies would be extremely low, something likely to be the case with many upstream issues. Accordingly, a representative survey was used to assess levels of awareness, supplemented by two qualitative workshops used to elicit more elaborated understandings: the latter being used to gauge how beliefs about nanotechnologies might become constructed in public discourse in the future. These workshops were interactive, with the nature of nanotechnologies being described alongside the presentation of scenarios, and with the opportunity to ask questions of an "expert scientist" attending. ${ }^{9}$ Interestingly, the quantitative survey found relatively positive views (amongst those who were aware of and could provide a definition of the term), 
whilst the qualitative workshops were more mixed, with enthusiasm for benefits alongside concerns about long-term risks and control of nanotechnologies, a methodological point to which we return later.

In their final report, the academies made 21 wide-ranging recommendations addressing: the industrial application of nanotechnologies; possible adverse health, safety and environmental impacts; regulatory issues covering the classification of nanomaterials, the workplace, consumer products and measurement; ensuring the responsible development of nanotechnologies; social and ethical issues; and stakeholder and public dialogue (RS/RAEng, 2004).

\section{Research methodology}

In the empirical research reported here, we study the impacts of the RS/RAEng nanotechnologies inquiry drawing upon a set of stakeholder interviews, conducted in the period immediately after the publication of its final report at the end of July-specifically, from August 2004 to January 2005. The broad aim of these interviews was to understand how the inquiry process, and its recommendations, had been positioned by both individuals with an interest in the emerging debate on nanotechnologies, and those involved in science communication and public engagement more generally. Not only does this provide insight into some of the tensions and dilemmas that surround different interpretations of the concept of "upstream public engagement," in addition it also provided an opportunity to analyze understandings of an inquiry which can in itself be positioned as "upstream," in terms of both process and recommendations. We conducted 24 interviews with a range of stakeholders; including individuals who had worked on the RS/RAEng inquiry group, others from nanoscience and nano-industry, as well as from science and technology studies and science communication. We also interviewed representatives from civil society groups and government. We have chosen to group interviewees into categories to help contextualize their comments within their relationship to nanotechnologies and society yet maintain the anonymity of those we spoke to (see Table 1 for a breakdown of interviewees). The majority of individuals contacted readily agreed to be interviewed, and expressed interest in the project. However, at the time of the fieldwork, a number of government representatives contacted stated that they could not discuss the report with us because the government was at that time working on its own response. As this has now been published (see HM Government, 2005) we refer to this response to the RS/RAEng report in this paper as appropriate.

The semi-structured interviews lasted approximately an hour each, were held either in person or by telephone, and were subsequently fully transcribed. Interviewees were first

Table 1. Interviewees

\begin{tabular}{lc}
\hline Science, Nanoscience and Nano-industry \\
(two are RS/RAEng Working Group members) \\
$\begin{array}{l}\text { Civil Society groups } \\
\text { UK Science and Technology Studies } \\
\quad \text { and Science Communication }\end{array}$ & 6 \\
$\begin{array}{l}\text { US Science and Technology Studies } \\
\quad \text { and Science Communication }\end{array}$ & 5 \\
$\begin{array}{l}\text { Royal Society and Royal Academy } \\
\quad \text { of Engineering Secretariat }\end{array}$ & 2 \\
$\begin{array}{l}\text { Government and Regulation } \\
\text { Total interviewees }\end{array}$ & 2 \\
\hline
\end{tabular}


invited to discuss the RS/RAEng processes, their prior expectations and subsequent impressions of the report. Following this, the majority of the questions centered around the relationship between nanoscience and society. Interviewees were also asked about their understanding of the notion of dialogue with the publics on nanotechnologies, and a number of specific recommendations that we discuss in the paper that we see as having "upstream" potential.

\section{Differing expectations/broadening input}

Despite the general enthusiasm for early societal attention to nanotechnologies, as noted above, the initial announcement that the RS/RAEng were to undertake the inquiry met with mixed responses. To some interviewees, particularly those from the science and business communities, involvement of the two academies represented both a way of opening up a range of under-researched scientific questions (such as the toxicology of nanoscale air pollutants) while also approaching the wider questions nanotechnologies raised in a relatively impartial manner, grounded in current scientific understandings and the "facts" of the matter. In particular, the involvement of the two academies was seen by these interviewees as an opportunity to put the debate about nanotechnologies on a more "balanced" footing. Interestingly, alongside the more dystopian visions of some critics, this was also thought necessary with regard to some of the more speculative claims being made by the technology's more vocal advocates. For example:

I had always been concerned that nanotechnology was being significantly over-hyped, that it was being misrepresented and that the reality was going to fall far short of some of the hype so I was looking forward to basing the report on hard scientific fact if you like, that removed a lot of the hype.

Interviewer: What would be examples of those?

I think it extends from the Drexler view of molecular manufacturing, spontaneous creation of materials, structures or devices through molecular assembly as being just as far away from anything we knew physically at the time, purely science fiction and also highly misleading, and because of the connotations of life and self replication it added a dangerous edge to perception. The other side is claims that it's going to be a universal panacea. That it was going to cure cancer, make computers the size of pinheads and so on. (Nanoscientist and RS/RAEng Working Group member)

By contrast, other interviewees reported having initial concerns about the inquiry process, something partly due to the reputation of government sponsored inquiries in general, and partly due to the ways in which they viewed the past track records of the two academies. Regarding the former issue, a body of academic literature exists critiquing the roles formal inquiries have often played in the past. For example, it is argued that inquiries can sometimes perform solely rhetorical functions, by providing legally non-binding advice at the same time as giving the public the impression of review and control, while in effect postponing governmental action and responsibility (Burton and Carlen, 1979). When formal inquiries are used to investigate a controversial, or potentially controversial issue, it has also been suggested that they have at times been carried out to "subdue" the voices of powerful pressure groups, particularly when there is the possibility that these groups may threaten the continuation of officially condoned activities. As such, they have been used at times in the past to portray continued opposition to an issue as unreasonable (Doyle and McEachern, 2001). 
It has also been argued that official inquiries have been employed as a way of addressing a multifaceted issue when a bureaucracy's resources are stretched and to maximize opportunities for a specific group of stakeholders (Ashforth, 1990), such as technology promoters or investors. Moreover, inquiries have sometimes been structured in ways that, either explicitly or implicitly, create obstacles to broader participation by constraining input and objections (see Rogers-Hayden, 2004; Rogers-Hayden and Hindmarsh, 2002; Rogers-Hayden and Jones, 2007; Walls et al., 2005). These critiques have focused on the (re)production of dominant power/knowledge systems through the structure of inquiries. Hindmarsh, reflecting upon Michel Foucault's interpretations (for example, 1977), refers to such inquiries as "regulatory legitimisers" as these are used to both "manage" problem populations and secure public trust and acceptance (Hindmarsh, 2003).

Accordingly, and echoing some of these critiques of inquiries more generally, there was concern from other stakeholders, particularly those with a social science, science communication or civil society background, that the inquiry would be used to take nanotechnologies out of public discourse: that is, serve as a means of pre-empting public debate and through this avoiding controversy. One interviewee echoed a number of others' comments when saying:

... it looked like it was an attempt by the political establishment, by particularly [Lord] Sainsbury [Minister of Science] and all, to bury or to defer discussion on nanotechnology ... like a way that they could put off any kind of discussions and also of course it looks like they were giving it to a trusted party i.e. a trusted party who would be expected to say the things they want them to say and that's from the history of the GM debate and the way in which the Royal Society has spoken on things like nuclear power and so forth. Yes, we were kind of expecting a political management of the issue rather than real discussion. (Civil Society member, interview, 2004)

The skepticism expressed by such interviewees also clearly related to the perceived histories of the academies too. That is, as the quotation above suggests, that the choice of the academies to conduct the work was seen by some to send a clear signal about the findings the government was seeking and/or would get, from the inquiry. Despite the inquiry's wider brief, which specifically included investigating the ethical and societal implications related to nanotechnologies (RS/RAEng, 2004: vii), there was a concern about how the academies had approached other controversial issues (e.g. nuclear power and genetically modified agriculture) in the past. The academies were portrayed by such interviewees as typically approaching the questions within a strictly science/progress frame. However, as noted above, the RS/RAEng study group composition and inquiry process differed markedly from previous inquiries undertaken by the Royal Society or Royal Academy of Engineering, as well as many of those critiqued in the academic literature. As a representative of the academies stated:

it's fair to say it's an unusual working group and for good reasons; it's an unusual project. We don't normally set out to look at the social and ethical issues in as much detail as we would science. It might be a sideline. (Royal Society/Royal Academy of Engineering representative)

Thus, a key difference in this inquiry was not just because the inquiry was occurring at the leading edge of research and development (which it undoubtedly was), as well as before public controversy and significant applications of nanotechnologies had emerged, but also because it was an important and successful collaboration between numerous stakeholders, in this way moving beyond science and engineering to significantly broaden the range of expertise involved.

Extending the expertise of the group, in addition to broadening the debate about nanotechnologies within the inquiry itself, also acted to expand the discourse of nanotechnolo- 
gies into sectors that were not, or not very, engaged with it at that stage. For example, although some civil society groups, such as the ETC group, ${ }^{10}$ had been working on nanotechnology issues for a number of years, Friends of the Earth (FoE) hadn't been deeply involved in the topic (Civil Society member, interview, 2004) and the UK's National Consumer Council hadn't looked into nanotechnologies before the inquiry (Civil Society member, interview, 2004). Thus the act of the inquiry in itself spurred learning of and engagement in the issues amongst these civil society stakeholder groups. The stimulation of nanotechnologies discourse amongst relevant stakeholders is the key reason that the inquiry was in itself positioned by many as "upstream"-and it is a point we will return to.

The broad range of expertise on the working group was significant not only in opening up debate but also in getting the attention of a number of commentators about the uniqueness of the process. It was one of the first "flags" a number of stakeholders saw as signifying a change in the practices of the academies and consequently it meant a change in their expectations of the inquiry. A number of interviewees who had voiced skepticism of the process reported that, on learning of the range of expertise represented on the independent working group, they had revised their initial expectations for the inquiry.

They [the academies] haven't had a good track record looking at things from a more public perspective so I was a little bit worried that this might be very much science orientated and "these are going to have a lot of economic benefits" and "aren't we great", "we are doing all this fab research" ... but when I found out who was on the panel [working group] ... I thought that's okay. (UK Science Communicator, interview, 2004)

The working group, in being such a diverse group, was therefore seen as having the potential to significantly broaden the framing of the issues under investigation (cf. Stirling, 2005). This meant, in particular, paying early attention to potential social and ethical issues of nanotechnologies rather than merely seeing social and ethical issues as post-production "impacts," a point to which we return later. Reflecting on the publication of the report itself, most of our interviewees who had originally been skeptical suggested that the actual outcomes had indeed avoided a narrow framing, in a way that did appear to reflect the innovative composition of the working group.

I think it was very much as good if not better than anyone could have expected from an institution like the Royal Society ... largely no doubt due to the fact that there was this more broadly constituted group so I was very pleased with it, it's an authoritative significant piece of work. (Civil Society member, interview, 2004)

Where points of criticism were expressed by such interviewees it was not with regard to the report's framing of the issues, but rather to the extent to which the report might have explored some of the societal questions (e.g. regarding governance of nanotechnologies, future ethical issues, or public "attitudes") in greater depth than it ultimately did.

\section{The contested notion of "upstream" dialogue}

A central recommendation of the RS/RAEng report was that there should be an "adequately funded public dialogue around the development of nanotechnologies" (RS/RAEng, 2004: Stakeholder and Public Dialogue Recommendation 19). In its own response to the RS/RAEng recommendation on dialogue, the UK government stated that " $[\mathrm{t}]$ he government agrees with this recommendation and is committed to promoting constructive dialogue on nanotechnologies" (HM Government, 2005: 20). The government's response also included an Annex 
describing principles for public dialogue on science and technology (POST, 2001). Significantly, however, the word "upstream" does not appear in this response document, despite it being stressed often in the RS/RAEng report.

The call for dialogue about science and technology is, of course, not unique: what is unusual is the proposed timing of any such dialogue. Thus, it is significant that the RS/RAEng recommend early debate but moreover that the RS/RAEng did this at a time when "upstream" dialogue was still possible, a point we will return to. The general case for wider societal dialogue about novel technologies, and with it greater openness about science policy, rests upon three broad sets of argument, which Fiorino (1990; see also Pidgeon, 1996; Stirling 2005) characterized as normative, instrumental and substantive. The normative argument suggests that dialogue is a good thing in and of itself, as one part of the process of resolving controversial decisions. The belief is that, by making such decisions sensitive to the ethical and value concerns of directly affected groups or populations a genuinely democratic approach to the governance of science and technology, together with its risks, can be forged (Pidgeon, 1998). By the instrumental argument, dialogue is a means of bolstering the legitimacy of decisions, and through this to enhance such things as trust in the policy-making process (Beierle and Cayford, 2002). It is significant that it is precisely this justification that had dominated many discussions of public engagement amongst the UK science policy community following BSE (e.g. House of Lords, 2000). Finally, the substantive argument is that dialogue and engagement, as part of a wider process of technology assessment, will help to generate better quality outcomes. In particular, the US National Research Council report on Understanding Risk (NRC, 1996) develops a detailed set of proposals for an "analytic-deliberative process," including extensive stakeholder engagement. This combines sound science and systematic uncertainty analysis with deliberation by an appropriate representation of affected parties, policymakers, and specialists in risk analysis. Such dialogue and deliberation should occur throughout the process of risk characterization, from problem framing through to detailed risk assessment and then on to risk management and decision implementation. Failure to attend to dialogue at the early stages of problem framing can be particularly costly, for a key concern may then be missing in subsequent analysis, potentially invalidating the whole process. This core issue of decision framing and risk is central to the substantive case for dialogue around upstream issues such as nanotechnologies (see Pidgeon and Rogers-Hayden, 2007).

The RS/RAEng recommendation for dialogue was met with support from many of our interviewees across the broad range of opinion sampled. For example:

I think this is probably the most significant area of the report, in the sense that, and I feel this quite strongly, that all new technologies need public acceptance otherwise they just won't take off ... It seems to me we have to get the public more informed, more involved. (Nanoscientist and RS/RAEng Working Group member)

I think ultimately the long-term health of a nano-enabled society (I don't know if that is quite the right word) will depend upon the degree to which we get various stakeholder and public groups engaged, talking about these issues ... and another thing I think is good, you [the RS/RAEng] are pretty clear with this report, you [the RS/RAEng] call it upstream, we have a chance to change the model in which science and technology interact with society. (US Science and Technology Studies academic, interview, 2004)

However, the contrast between the quotes above hints at a range of more fundamental underlying tensions, surrounding the question of what such engagement might ultimately be for and the notion of "citizenship" included in the model of participation being assumed (Irwin, 2001; Rayner, 2003; cf. also Toumey, 2006). In this respect a number of interviewees hotly 
contested the notion of "upstream engagement," in particular expressing ambivalent attitudes towards its purposes. This interviewee's comments summed up a great deal of discussion on the use and potential misuse of upstream debate on nanotechnologies.

I don't really know whether [early engagement is] a good thing or a bad thing. Sometimes I think it's quite a bad thing because you are manipulating people by saying now you've had the conversation about it so you've had your say and everything's alright.

(UK Science and Technology Studies academic, interview, 2004)

As well as the possibility that engagement might circumscribe debate, upstreaming was seen as potentially being used for democratizing technology, improving technology and for "getting people on side" (mentioned both as a positive use and as a manipulation of dialogue by various interviewees). This raises the possibility that early engagement could, in Stirling's (2005) terms, be used either to close down or open up debate, depending on how the dialogue is constructed and the issues framed. In the following subsections we explore some of the associated tensions and dilemmas.

\section{Shaping science or public opinion?}

One of the advantages of viewing nanotechnologies as an upstream issue is that it suggests that lessons can be learned from the history of other controversial technological innovations such as in biotechnology (see for example Mayer, 2002; Mehta, 2004; Grove-White et al., 2004; Einsiedel and Goldenberg, 2005), civilian nuclear power (Flynn, 2003), the chemical industries, or others that have held the potential for significant controversy (such as human reproductive technologies). Mayer (2002), for example, suggests that by viewing the development of major technologies as social processes, there are clear parallels to be drawn between nanotechnologies today and the position that biotechnology faced in the 1980s. She argues that similarities include the levels of extreme excitement and hype, a promise to control the future without critical consideration first of which futures are desirable and who might control them, and debates narrowly framed about the issues of risk. Accordingly, advocates of upstream engagement see its role as shaping a wide agenda-that of the dynamic of science and technology itself. Hence, Wilsdon (2004; Wilsdon et al., 2005) argues that for public engagement to be truly upstream it should invoke a range of questions that challenge the agendas and practices of science itself, rather than solely the present or future representations that a society might hold about that science: "Why this technology? Why not another? Who needs it? Who owns it? Who will benefit from it? Can they be trusted? Who will take responsibility if things go wrong?"

The framing of nanotechnologies was mentioned by a number of our interviewees. The following quote stresses a perceived need to change the relationship between science and society, proposing that nanotechnologies have arrived at a time when the traditional view of "public understanding of science," in which scientists were seen as the principal people qualified to judge, or make decisions about, technologies would no longer be accepted by society. The interviewee stressed that blanket assurances from scientists, in the sense of one-way communication, would not work. "There's no point in experts anymore standing up telling people there are no dangers, they don't believe them" (Nanoscience and Nano-industry member, interview, 2004).

However, a generally low level of public awareness about nanotechnologies, and the introduction of nanotechnologies at a time when government and industry have become acutely aware of the shortcomings of perceived (mis)management of earlier technologies, such as agricultural GM, was also noted by many of the interviewees. Comments in particular mentioned the potential this combination held for science-society relationships. Early 
dialogue was also seen as a way of "getting in early" by a number of interviewees, not only to open up genuine communication between science and society, but also by some as an opportunity to "educate." Paradoxically, undertaking public dialogue on nanotechnologies while there is so little existing public knowledge of them was also seen to carry risks for the field, expressed as a concern that "there is a danger in opening a dialogue that the media will seize upon it and it will become alarmist" (Government/Regulator, interview, 2004). In this sense, the claim was that while early public dialogue held the potential to shape the agenda of public discourses, it might contribute to an amplification of concerns about risk, reinforced through contemporary representations of nanotechnologies within science fiction (many of which can be interpreted either favorably or unfavorably). The extent to which dialogue processes do contribute to the social amplification or attenuation of risk perceptions for participants is an important question, albeit one about which we know very little at present (for one exception see Renn, 2003).

Public opinion about nanotechnologies was thus seen by some of our interviewees as still open for formation. The opportunity for science to "get in first," and "set the record straight," and in particular before popular scenarios became dominant in public discourse was mentioned by some interviewees. In this way the publics could be made aware of the "real" risks and opportunities offered by nanotechnologies. Early public engagement was thus seen as having both the advantage and disadvantage_-depending on one's viewpoint—of being used to shape the emergent societal discourses about nanotechnologies and their acceptability. Seen from a critical perspective then, enthusiasm for upstream engagement might simply be replacing (but in effect does not supplant) the older style of science communication. That is, possible objections to the technology might now be readily attributed to a deficit in public engagement rather than a deficit in public knowledge (as the 1980s model of science communication had supposed; critiqued in Irwin and Wynne, 1996), an elision with rather less radical potential than might first appear. Hence:

... it's a kind of deficit model again, a deficit model of public engagement-we'll dialogue in order so that they understand us better and will agree with us, instead of we'll sit them down and educate them. Substitute the word dialogue for the word education but with the expectation ... you can read a lot of stuff where the expectation is that when the dialogue is finished scientists can just carry on as normal. I'm sorry it doesn't work like that. If you have a dialogue then that means you are listening and you're taking notes and you're changing as a consequence. As I say, I see absolutely no evidence that anybody who I would call in serious authority or in charge has got any intention of doing any of that whatsoever. (Civil Society member, interview, 2004)

Rayner (2004) identifies three deficit models in the development of contemporary sciencesociety relationships. The first, as described, being a perceived lack of understanding of the science by the publics, the second being a change in rhetoric by science communicators while they talk about two-way communication and still provide "information" to the publics, and the third being a perceived deficit in "trust" in institutions by the publics. From this perspective the perceived deficit in dialogue identified here could be seen as a fourth type of deficit model.

All of this sets a dilemma for the design and conduct of upstream engagement processes, since it is hard to see how the goals of opening up the research agenda to more public scrutiny on the one hand can be reconciled with a push to use engagement to shape public discourses on the other. On a practical level the danger is that, as with the UK GM Nation? public debate which occurred in 2003 (see Horlick-Jones et al., 2007), engagement will be compromised from the outset by incompatible objectives. Equally, either of these objectives-being broad in scope and ambition-would seem difficult to attain through a program of public engagement alone. 


\section{Impacts or interaction?}

Our interviewees also highlighted that the role of nanotechnologies in the evolving debates about the relationship between science and society is likely to be a contested issue. Some interviewees thought that such debates shouldn't be linked specifically to nanotechnologies, while others suggested that linkage was helpful in so far as it brings some of the critical science-society issues to the fore. In particular, nanotechnologies is not a single technology but rather points, in the medium and longer term, to a convergence of technologies in ways that might have profound societal consequences (for example, nanotechnologies with information technology, biotechnology and cognitive science; see e.g. Roco and Bainbridge, 2003; Wood and Jones, 2003: Nordmann, 2004). In this sense, a number of interviewees thought discussion shouldn't, or even can't, be contained to the topic of nanotechnologies.

The debates we are having around nanotechnology are really around technology per se and the fact that nanotech is such a broadly framed field itself encourages that. Some people see that as a disadvantage ... But for me, precisely because these debates are not really about risk primarily, they are about the democratization of technology choice, then it's an advantage that the technology on which they are essentially focused is so disparate. This helps to draw out the generic features, and highlight that the real debate is about the governance of technology in general. So I think in that sense the issues go far wider than nanotech and it's right that they should. (UK Science and Technology Studies academic, interview, 2004)

Nanotechnologies are thus seen as allowing a platform for public participation-as a necessary change in governance to discuss wider issues of science-society interactions. The RS/RAEng report itself recommended (2004: 87, Recommendation 21) "that the Chief Scientific Advisor should establish a group that brings together representatives of a wide range of stakeholders to look at new and emerging technologies and identify at the earliest possible stage areas where potential health, safety, environmental, social, ethical and regulatory issues may arise and advise on how these might be addressed." This recommendation emerged within the inquiry as a response to concerns that the unintended impacts of developments in nanotechnologies, as part of wider technological dynamics, might be emergent (that is, only recognizable at some unspecified future point in time), as well as a product of currently unanticipated convergences of technology, and hence could only be debated "upstream" if first identified through some form of ongoing reflective oversight. There was considerable support for this recommendation amongst our interviewees, who also stressed that this should be applied to a range of technologies; that is, it was not an issue confined to nanotechnologies but encompassed a range of future developments.

I feel that nanotechnology is just the technology that we're discussing today. Next year it will be something else and it seems to be not really satisfactory just to be dealing with hot topics when they arrive, it really should be something that the Government should be doing as a matter of course. As long as it doesn't become a talking shop. (Nanoscience and Nano-industry member, interview, 2004)

In the government's own response it stated that as part of its 10-year investment framework for science and innovation it was creating a center of excellence in science and technology horizon scanning to be based in the Office of Science and Technology and overseen by the Chief Scientific Advisor, building in particular on existing foresight scanning capacity (HM Government, 2005: 21). Whether the government's own group meets the potential held out for it, or falls somewhat short of this, as suggested by Wilsdon, Wynne and Stilgoe (2005: 57), 
the recommendation does hold the potential to offer a catalyst for change, through a new more open approach to the relationship between science and society. However, rather than look at impacts on people from existing technologies, upstream technology assessment might address more productively the interaction between new technologies and society (cf. Rip et al., 1995; Einsiedel and Goldenberg, 2005). As one interviewee suggested:

Let me put in a plug for a simple word change ... "Impact" is a difficult word. I think it's better to think of perhaps "interaction". (US Science and Technology Studies academic, interview, 2004)

It's a small but significant word change from downstream social and ethical impacts to upstream public interactions with the technologies. Without an emphasis on "interactions" rather than "impacts," the role of the publics in relation to nanotechnologies is always likely to be confined to the "downstream" or post-production phase. This can be seen in the way Ethical, Legal and Social Issues (ELSI) is currently positioned in the US for the development of the Human Genome Project, and is also, in turn, setting the intellectual and institutional context for considering nanotechnologies in the US. The ELSI model, which has been critiqued for stimulating discussion rather than affecting policy development (Fisher, 2005), can be seen as framing technologies as inevitable and autonomous, leaving no room for evaluation of such impacts to affect the development of the technologies themselves (Macnaghten et al., 2005). There has even been the development of a similar specific acronym for nanotechnologies-SEIN_-societal and ethical impact of nanotechnologies (US Science and Technology Studies academic, interview, 2004).

Taking the metaphor of interaction seriously means assessing the suitability of technologies for society rather than assuming that society passively accepts technologies which are value and power neutral and thus "given." What this might in turn open up is more explicit analysis within participatory processes of the often hidden assumptions about the power relationships between technologies and society, by acknowledging that there are multiple paths technologies could take/or could have taken that are not always visible (see Hill, 1998). Upstream engagement, in this instance, may even provide a means of placing on the table topics that typically remain outside of traditional discussions of the trajectory and conduct of science: in particular the power relations a technology embodies, and the balance between corporate and civil society interests and control.

\section{Opening up science?}

The theoretical position hinted at above, in which society is not simply impacted by technologies, but itself interacts with science and technology, enables one to view science-society relationships as mutually constitutive. In this way science can be seen, like all knowledges, to reflect its social and historical origins: the culture, politics and values of a society. Opening up the "black box" of science to expose the values permeating it is a commonplace call within science and technology studies (see Jasanoff, 2005; Leach et al., 2005) but less common in the natural sciences. Upstreaming engagement, and with it a promise of an increase in genuine science-society interaction, means that science and scientists learn from the publics as much as citizens learn from science. In effect this represents a call for greater reflexivity within science, in which scientists engage with whatever values underlie their work and what values will be reproduced through their work.

The RS/RAEng report acknowledged that the case of nanotechnologies highlighted a need to go beyond public dialogue: in effect to find ways to open up science itself. Recommendation 17 states that: 
The consideration of ethical and social implications of advanced technologies (such as nanotechnologies) should form part of the formal training of all research students and staff working in these areas and, specifically, that this type of formal training should be listed in the Joint Statement of the Research Councils'/AHRB's Skills Training Requirements for Research Students. (RS/RAEng, 2004: 87)

Part of the significance of this recommendation is that it also turns attention away from the downstream entry or impacts of technologies within society, to the upstream visions for new technologies as they are developed. Social and ethical issues are thus no longer post-product add-ons but positioned as integral to the creation of new knowledge. The UK government supported this idea in principle, yet also suggested that mechanisms are already in place to address this, through workshops, public debates, skills training and other activities which could be developed further by the existing research community (HM Government, 2005). Most of our own interviewees, however, interpreted this recommendation more broadly than this. For example, the following interviewee, from the nanoscience community, suggested that this type of discussion amongst scientists and science students would probably be most welcome-and something not often undertaken in the physical sciences.

My guess is that young people would be quite interested and enthusiastic. I have to say also that on the physical sciences side there has been less activity than in the biological sciences because in the biological sciences we get these issues cropping up all the time whether it's GM or stem cells ... On the physical sciences, there doesn't seem to be, to put it bluntly, not much of an ethical issue about a transistor so is there any need to deal with, devote a lot of time to that area? My guess is probably not, but on the other hand new technologies have an impact on society; who benefits from them, who owns them, who controls them, who controls the development. I think there are issues in there which certainly deserve exploring. (Nanoscience and Nano-industry member and RS/RAEng Working Group member, interview, 2004)

In this passage the interviewee highlights the importance of scientists knowing some of the social and ethical implications of the projects they are working on. Some in nanotechnology industries do indeed see learning about public concerns and taking possible risks seriously as a part of learning from what they see as the past "public relations disasters" of nuclear energy and GM. Nanotechnologies are therefore seen to provide the opportunity to forge a different relationship with citizens as the technologies develop (Physics Today, 2004). Yet the interviewee quoted above also highlights deeper questions for scientists to explore about the social context of technologies. Thus, rather than trying to just anticipate publics' concerns and avoid damaging publicity through knowledge about publics' values, this approach demands a stronger social awareness from scientists. Although most interviewees supported the idea of moving the entry point of discussion on social and ethical implications further up the technology production process, there were some additional concerns expressed about potential misuse of this approach (in addition to concerns about the level of support scientists would get to achieve this, and demands on scientists' time and energy). Many interviewees emphasized that the relationship between science and society was much broader than merely scientists discussing the implications of technologies. In this way, rather than formal "training," a new approach to democratizing technology was needed, one enabling a greater reflexivity within the sciences. One such experiment was carried out at the Interdisciplinary Research Centre (IRC) at Cambridge University UK, partly influenced by the RS/RAEng inquiry. The Centre employed Robert Doubleday, a sociologist with a chemistry background, to foster activities explicitly bridging the science-society divide. Doubleday was involved in activities 
involving nanoscientists, stakeholders, and citizens. ${ }^{11}$ Of particular interest to this discussion is that he is creating courses for nanoscience students which go beyond merely describing public concerns about technologies but move towards a reflexivity in science by placing the technologies within this social and historical context.

\section{Concluding considerations: the perils and promise of upstream?}

I'm certain it [upstream dialogue] is not the panacea that some folks see it as being. (UK Science and Technology Studies researcher, ${ }^{12}$ interview, 2004)

The upstreaming of debate on nanotechnologies will not provide all of the answers to science-society relationships, but it does provide the opportunity to try something different, through creating an early entry point for public dialogue. The RS/RAEng inquiry that we have analyzed here provided an insight into the potential upstream dialogue holds, through engaging a wide range of stakeholders in discussion (the reason the RS/RAEng was positioned as "upstream" by commentators), and recommending further potential pathways for upstreaming the relationship between science and society (in their explicit and implicit notions of upstream).

There does seem to be widespread support for broad engagement on the issues surrounding nanotechnologies: RS/RAEng (2004) clearly recommended this; the government agreed with this recommendation; and a number of such processes are currently taking place in the UK. However, exploring multiple perspectives on nanotechnologies through early engagement doesn't necessarily mean that controversy will be avoided or even that this should be/is a goal of early engagement. Upstream dialogue shouldn't recreate a new deficit model, in which objections to aspects of new technologies are seen as occurring, no longer from a lack of public understanding of science, but from a lack of early public engagement. Indeed, upstream dialogue may even lead to even greater differences of opinion than seen with downstream issues, as debate revolves around (possibly incommensurable) visions for the future of society when technologies are still being conceived. Moreover, early dialogue also raises the question, not only of the goals of debate, but of how the relationship between participation and policy outcomes might operate. Evidence with traditional forms of public participation suggests that this can quickly lead to anger and stakeholder fatigue if they do not appear to be linked to policy consideration (Rayner, 2003). Additionally, as Rayner also points out, establishing a linkage between deliberative processes and policy outcomes is inevitably difficult at the best of times and moving debate upstream is unlikely to make this situation any easier.

Further, as yet unaddressed questions, include the implications of dialogue when there are so few products, scenarios and examples to discuss, and so much remains hypothesis. For example, is it impractical, or even necessary, to spend time entertaining Drexlerian imaginaries and visions? Equally, as discussion of nanotechnologies is likely to be based on future developments with essentially unknown consequences, upstream debate becomes dialogue with even greater uncertainties and indeterminacy. It may be not only impossible to predict outcomes but also impossible to know what we don't know about nanotechnologies (see Deville and Harding, 1997; also Wynne, 1992). Can this contribute to a situation in which opening up early debate creates an "issue" by simply amplifying perceived risks (see Pidgeon and Rogers-Hayden, 2007)? This may well be unlikely on the basis of engagement processes alone, as research on the social amplification of risks tends to suggest that this rarely depends upon any single factor operating alone, but upon the combined impacts of a range of factors accumulating over time - such as the balance of perceived benefits and risks between individuals, the private and the public sectors; analogies drawn with other (both stigmatized or accepted) technologies; the existence of significant scientific dispute; and attribution of blame 
for prominent accidents were these to occur; alongside significant media coverage and interest group attention (Pidgeon et al., 2003; Kasperson and Kasperson, 2005). As an example of the last, in their article "When Nano-Pants Attack" the journal Wired (2005) described Chicago activists walking into an Eddie Bauer store and taking off their clothes in the storefront window. They "aimed to expose more than skin: Activists hoped to lay bare growing allegations of the toxic dangers of nanotechnology." Painted on their bodies were messages such as "Eddie Bauer hazard" and "Expose the truth about nanotech," as the company has been seen to recently embrace nanotechnology with its line of stain-resistant "nanopants."

The general low awareness of nanotechnologies does, however, raise (at least two) specific methodological problems likely to be common to many upstream engagement contexts. First, because research methodologies for eliciting the views and values of dialogue participants are not necessarily neutral instruments, a problem that is likely to be magnified in upstream contexts where prior awareness is low. We can compare the rather different quantitative and qualitative findings found by the RS/RAEng. Their survey approach presents a relatively positive picture of current British public opinion on nanotechnologies, ${ }^{13}$ while the workshops were far more mixed. In social science terms, both approaches have strengths and limitations of course, although one can argue that there are good grounds to place particular emphasis upon the qualitative findings, not least because they are the product of a more deliberative exchange by the participants. However, the fact remains that selection of research methods might have a significant influence upon the data collected and hence the conclusions reached from any upstream engagement process.

The second methodological problem arises because, under circumstances of low prior awareness and knowledge, the provision of good quality information to dialogue participants will be critical. In one sense this begins to map out some of the design parameters for upstream engagement processes, or at least to rule out some methodologies and sampling strategies in advance. However, one danger here is that debate may be inadvertently framed by the organizers in a particular way; for example stressing the positions of perhaps only one, or a limited set of voices to the debate. Equally, even in a citizen jury type format, where participants are (in principle) free to select their own evidence and witnesses, some prior framing will be necessary to initiate the engagement process. All of this will be particularly difficult where the basic "facts" of the matter are also contested by the different sectional interests (industry, non-governmental organizations, government etc.), something that is likely when an issue is highly uncertain and upstream.

What this does mean is that the framing of nanotechnologies is yet to come. With the push for early engagement gaining popularity there also needs to be a parallel call for welldocumented case studies. Amidst all of the current enthusiasm we urgently need further research on which dialogue processes might work (and will not work!) in the upstream phase of a technology's development. We certainly cannot assume that downstream techniques can readily transfer to the inherently more uncertain and turbulent world of upstream technology assessment and public deliberation. Such approaches may mean thinking beyond "dialogue" with the publics. It may mean involving a wider group of people/stakeholders in emerging technology assessment such as civil society, and science/industry/academia (rather than just government) and opening up the black box of science through ethics training for scientists. In this way, upstream engagement may well mean far more than just early public debate at a point prior to polarized opinions or significant research and development. Rather, it will involve an ongoing cycle ${ }^{14}$ of dialogue among affected parties. Therefore, the agenda will need to move from industry product based debate (found in downstream dialogue) to broader framing of the issues. This will involve unpacking the assumptions that go into science alongside exploring how technologies fit in with the forms of society that citizens wish to have. 
Thus ideally debating visions all parties have for society and how the technologies can/should/could and cannot be developed to fit within these. This path of deliberating societal visions and assumptions may even lead to exploring some more radical ways of approaching the interaction of citizens and science that have yet to be conceptualized. In the wake of the GM and BSE affairs in Europe, nanotechnologies may well have arrived at a time where there is a genuine opportunity to try something different. What is clear is that:

... there is an opportunity now which there won't be in three or four years time and probably wasn't three or four years ago to ask quite deep questions about new technology development trajectories ... in the UK it will be because the memories of the GM debate will fade, the furore will fade and so [will] the willingness of decision makers to take on board new lessons, new ways of working, new ways of thinking about things, lessons about technologies, society and interaction ... It's a political opening not a technological one although it does coincide with a technological one. (Civil Society member, interview, 2004)

\section{Acknowledgements}

The authors would like to warmly thank everyone who agreed to be interviewed as part of this project, as well as Brian Martin, two anonymous referees and the issue editors, all of whom provided constructive comments. This research was supported primarily by the Leverhulme Trust as part of a program award to the Understanding Risk team at the University of East Anglia. Part support is also acknowledged from the US National Science Foundation (grant no. 0531184) to the Center for Nanotechnology in Society, University of California Santa Barbara. Nick Pidgeon was also a member of the Royal Society and Royal Academy of Engineering nanotechnologies inquiry working group.

\section{Notes}

1 While stakeholder engagement refers to dialogue with specialized communities involved with nanotechnology, be they civil society, academia or government, public debate refers to dialogue with individuals or groups beyond these specialized communities: see Schiappa (1989).

2 We are choosing to use the words "engagement," "debate" and "dialogue" interchangeably throughout the paper to reduce repetition.

3 It is something of a misnomer to refer to nanotechnology in the singular as the term encompasses such a wide variety of applications. For this reason we will be referring to the plural nanotechnologies throughout the paper where practical.

4 In line with STS (Science and Technology Studies) convention we are using the plural of the public_- "publics." The intention is to acknowledge that there are multiple identities and standpoints within society, and hence not just one public perspective or voice on this issue.

5 The question of whether a crisis of trust in science actually existed at this point in time is debatable. At the level of general beliefs about the contribution of science and technology to society, public attitudes have remained highly favorable in the UK (see OST/Wellcome, 2000; OST/MORI, 2005). Where concerns are expressed it is with respect to much more specific controversial issues (radioactive waste, GM food, the MMR (measles, mumps, and rubella) vaccine).

6 In particular, among the 15 members were Onora O'Neill an ethicist from the University of Cambridge, Deirdre Hutton from the UK National Consumer Council, the environmentalist and Chair of the UK Sustainable Development Commission Jonathon Porritt, and Nick Pidgeon as social scientist.

7 The survey is not included in the processes we are referring to when we suggest that the RS/RAEng was positioned as "upstream" by commentators, as this was primarily an information gathering process rather than an engagement process.

8 Following the successful precedent set with the nanotechnologies inquiry, a subsequent Royal Society (2005) report on pharmacogenetics also elicited public views, in collaboration with the organization's "Science and Society" program.

9 The scientist's role was confined to providing basic information on what nanotechnology was, scenarios of possible developments in nanotechnology, and then to be "on hand" to answer questions raised by the group. 
10 See ETC, http://www.etcgroup.org

11 For example Doubleday was also involved in Nano Jury UK - the first citizens' jury on nanotechnology.

12 This interviewee preferred to be called a researcher rather than an academic.

13 A similar finding for the United States is reported in Sims-Bainbridge (2002).

14 For a discussion on types and timing of dialogue in an engagement cycle see Jackson et al. (2005).

\section{References}

Ashforth, A. (1990) "Reckoning Schemes of Legitimation: On Commissions of Inquiry as Power/Knowledge Forms," Journal of Historical Sociology 3(1): 1-22.

Beierle, T.C. and Cayford, J. (2002) Democracy in Practice: Public Participation in Environmental Decisions. Washington DC: Resources for the Future.

Bjiker, W.E., Hughes, T.P. and Pinch, T., eds (1974) The Social Construction of Technological Systems: New Directions in the Sociology and History of Technology. Cambridge, MA: MIT Press.

Burton, F. and Carlen, P. (1979) Official Discourse: On Discourse Analysis, Government Publications, Ideology and the State. London: Routledge and Kegan Paul.

Collingridge, D. (1992) The Management of Scales: Big Organizations, Big Decisions, Big Mistakes. London: Routledge. Deville, A. and Harding, R. (1997) Applying the Precautionary Principle. Annandale: Federation Books.

Doyle, T. and McEachern, D. (2001) Environment and Politics. London: Routledge.

Einsiedel, E. and Goldenberg, L. (2005) "Dwarfing the Social? Nanotechnology Lessons from the Biotechnology Front," Bulletin of Science, Technology and Society 24(1): 28-33.

Fiorino, D.J. (1990) “Citizen Participation and Environmental Risk: A Survey of Institutional Mechanisms," Science, Technology and Human Values 15: 226-43.

Fisher, E. (2005) "Lessons Learned from the Ethical, Legal and Social Implications Program (ELSI): Planning Societal Implications Research for the National Nanotechnology Program," Technology in Society 27: 321-8.

Flynn, J. (2003) "Nuclear Stigma," in N.F. Pidgeon, R.K. Kasperson and P. Slovic (eds) The Social Amplification of Risk, pp. 326-54. Cambridge: Cambridge University Press.

Foucault, M. (1977) Discipline and Punish. Harmondsworth: Penguin.

Grove-White, R., Kearnes, M., Miller, P., Wilsdon, J. and Wynne, B. (2004) "Bio-to-Nano? Learning the Lessons, Interrogating the Comparison," Working Paper Series 2004/5. Lancaster: Institute for Environment, Philosophy and Public Policy, Lancaster University.

Hagendijk, R. and Irwin, A. (2006) "Public Deliberation and Governance: Engaging with Science and Technology in Contemporary Europe," Minerva 44: 167-84.

Hill, S. (1998) The Tragedy of Technology. London: Pluto Press.

Hindmarsh, R. (2003) "The Role of Regulatory Legitimisers in Policy Formation for Environmental Release of GMOs: Where to Next? Implications for Sustainability," Paper presented at the Ecopolitics XIV Conference "Sustainability: A New Goal for Human Endeavour?," 27-30 November, RMIT Melbourne, Australia.

HM Government (2005) Response to the Royal Society and Royal Academy of Engineering Report: Nanoscience and Nanotechnologies: Opportunities and Uncertainties. London: Department of Trade and Industry.

HM Treasury / Department of Trade and Industry / Department for Education and Skills (2004) Science and Innovation Framework 2004-2014. London: HM Treasury.

Horlick-Jones, T., Walls, J., Rowe, G., Pidgeon, N.F., Poortinga, W. Murdock, G. and O'Riordan, T. (2007) The GM Debate: Risk, Politics and Public Engagement. London: Routledge.

House of Lords Select Committee on Science and Technology (2000) Science and Society 3rd Report. HL Paper 38. London: HMSO.

Irwin, A. (2001) "Constructing the Scientific Citizen: Science and Democracy in the Biosciences," Public Understanding of Science 10: 1-8.

Irwin, A. and Wynne, B., eds (1996) Misunderstanding Science? The Public Reconstruction of Science and Technology. Cambridge: Cambridge University Press.

Jackson, R., Barbagello, F. and Haste, H. (2005) "Strengths of Public Dialogue on Science-Related Issues," Critical Review of Social and Political Philosophy 8(3): 349-58.

Jasanoff, S. (2005) Designs on Nature: Science and Democracy in Europe and the United States. Princeton, NJ: Princeton University Press.

Joss, S. (1998) "Danish Consensus Conferences as a Model of Participatory Technology Assessment: An Impact Study of Consensus Conferences on Danish Parliament and Danish Public Debate," Science and Public Policy 25: 2-22.

Kasperson, X.J. and Kasperson, R.E. (2005) The Social Contours of Risk, vol. 1. London: Earthscan. 
Leach, M., Scoones, I. and Wynne, B. (2005) Science and Citizens. London: Zed Books.

Macnaghten, P., Kearnes, M. and Wynne, B. (2005) "Nanotechnology, Governance and Public Deliberation: What Role for the Social Sciences?," Science Communication 27(2): 1-24.

Macoubrie, J. (2006) "Nanotechnology: Public Concerns, Reasoning and Trust in Government," Public Understanding of Science 15: 221-41.

Mayer, S. (2002) "From Genetic Modification to Nanotechnology: The Dangers of 'Sound Science,"” in T. Gilland (ed.) Science: Can We Trust the Experts?, pp. 1-15. London: Hodder and Stoughton.

Mehta, M.D. (2004) "From Biotechnology to Nanotechnology: What Can We Learn from Earlier Technologies?," Bulletin of Science, Technology and Society 24(1): 34-9.

Mnyusiwalla, A., Daar, A. and Singer, P. (2003) "Mind the Gap': Science and Ethics in Nanotechnology," Nanotechnology 14: 9-12.

Nordmann, A. (2004) Converging Technologies-Shaping the Future of European Society. Brussels: European Commission.

NRC (1996) Understanding Risk: Informing Decisions in a Democratic Society. Washington DC: US National Research Council.

OST/MORI (2005) Science in Society: Findings of Qualitative and Quantitative Research Conducted for the Office of Science and Technology, DTI. London: Department for Trade and Industry.

OST/Wellcome (2000) Science and the Public: A Review of Science Communication and Public Attitudes to Science in Britain. London: Office for Science and Technology/Wellcome Trust.

Phillips of Worth Matravers, Lord, Bridgeman, J. and Ferguson-Smith, M. (2000) The BSE Inquiry Report. London: The Stationery Office.

Physics Today (2004) “Scholars Probe Nanotechnology's Promise and its Potential Problems," June, pp. 3-32. URL: http://physicstoday.org/vol-57/iss-6/p30.html (accessed 30 November 2006).

Pidgeon, N.F. (1988) "Risk Assessment and Accident Analysis," Acta Psychologica 68: 355-68.

Pidgeon, N.F. (1996) “Technocracy, Democracy, Secrecy and Error," in C. Hood and D. Jones (eds) Accident and Design-Contemporary Debates in Risk Management, pp. 164-72. London: University College London Press.

Pidgeon, N.F. (1998) "Risk Assessment, Risk Values and the Social Science Programme: Why We Do Need Risk Perception Research," Reliability Engineering and System Safety 59: 5-15.

Pidgeon, N.F. and Rogers-Hayden, T. (2007) "Opening up Nanotechnology Dialogue with the Publics: Moving Beyond Risk Debates to 'Upstream Engagement,"' Health Risk and Society (forthcoming).

Pidgeon, N.F., Kasperson, R.E. and Slovic, P. (2003) The Social Amplification of Risk. Cambridge: Cambridge University Press.

Pidgeon, N.F., Poortinga, W., Rowe, G., Horlick-Jones, T., Walls, J. and O’Riordan, T. (2005) "Using Surveys in Public Participation Processes for Risk Decision-making: The Case of the 2003 British GM Nation? Public Debate," Risk Analysis 25: 467-80.

POST (1995) Plant Biotechnology: A Consensus. Report 56. London: Parliamentary Office of Science and Technology.

POST (2001) Open Channels: Public Dialogue in Science and Technology. Report 153. London: Parliamentary Office of Science and Technology.

Rayner, S. (2003) "Democracy in the Age of Assessment: Reflections on the Roles of Expertise and Democracy in Public-sector Decision-making," Science and Public Policy 30(3): 163-70.

Rayner, S. (2004) “The Novelty Trap: Why Does Institutional Learning about New Technologies Seem so Difficult?," Industry and Higher Education 18(5): 340-55.

Renn, O. (2003) "Social Amplification of Risk in Participation: Two Case Studies," in N.F Pidgeon, R.K. Kasperson and P. Slovic (eds) The Social Amplification of Risk, pp. 374-401. Cambridge: Cambridge University Press.

Renn, O., Webler, T. and Wiedemann, P. (1995) Fairness and Competence in Citizen Participation: Evaluating Models for Environmental Discourse. Dordrecht: Kluwer.

Rip, A., Misa, T.J. and Schot, J. (1995) Managing Technology in Society: The Approach of Constructive Technology Assessment. London: Pinter Press.

Roco, M. and Bainbridge, W. (2003) Societal Implications of Nanoscience and Nanotechnology. Dordrecht: Kluwer. Rogers-Hayden, T. (2004) "Commissioning Genetic Modification: The Marginalisation of Dissent in the Royal Commission on Genetic Modification," Unpublished doctoral thesis, Department of Geography, University of Waikato.

Rogers-Hayden, T. and Hindmarsh, R. (2002) "Modernity Contextualises New Zealand's Royal Commission on Genetic Modification: A Discourse Analysis," Journal of New Zealand Studies 1(1): 41-62.

Rogers-Hayden, T. and Jones, M. (2007) "Public Biotechnology Inquiries: From Rationality to Reflexivity?," in P. Glasner and P. Atkinson (eds) New Genetics, New Social Formations, pp. 49-68. London: Routledge.

Royal Society (1985) The Public Understanding of Science. London: The Royal Society. 
Royal Society (2005) Personalised Medicines: Hopes and Realities. London: The Royal Society.

Royal Society and Royal Academy of Engineering (2004) Nanoscience and Nanotechnologies: Opportunities and Uncertainties. London: Royal Society and Royal Academy of Engineering.

Schiappa, E. (1989) “'Spheres of Argument' as Topoi for the Critical Study of Power/Knowledge,” in B. Grinbeck (ed.) Spheres of Argument, pp. 47-56. Annandale: Speech Communication Association.

Sims-Bainbridge, W. (2002) "Public Attitudes Toward Nanotechnology," Journal of Nanoparticle Research 4: 561-70.

Stirling, A. (2005) "Opening Up or Closing Down? Analysis, Participation and Power in the Social Appraisal of Technology," in M. Leach, I. Scoones and B. Wynne (eds) Science, Citizenship and Globalisation, pp. 218-31. London: Zed Press.

Toumey, C. (2006) "National Discourses on Democratizing Nanotechnology," Quaderni 61: 81-101.

UKCEED (1999) UK National Consensus Conference on Radioactive Waste (Final Report). Peterborough: UK Centre for Economic and Environmental Development.

Walls, J., Rogers-Hayden, T., Mohr, A. and O'Riordan, T. (2005) “Seeking Citizens' Views on GM Crops: Experiences from the United Kingdom, Australia, and New Zealand,” Environment September: 22-36.

Wilsdon, J. (2004) "Dialogue is Moving Upstream," Science and Public Affairs December: 11.

Wilsdon, J. and Willis, R. (2004) See Through Science: Why Public Engagement Needs to Move Upstream. London: Demos.

Wilsdon, J., Wynne, B. and Stilgoe, J. (2005) The Public Value of Science: Or How to Ensure that Science Really Matters. London: Demos.

Wired (2005) "When Nano-Pants Attack," 10 June. URL: http://www.wired.com/news/medtech/0,1286,67626,00. html?tw=wn_tophead_2 (accessed 30 November 2006)

Wood, S. and Jones, R. (2003) The Social and Economic Challenges of Nanotechnology. Swindon: Economic and Social Research Council.

Woodrow Wilson International Center for Scholars (2006) A Nanotechnology Consumer Products Inventory (Project on Emerging Nanotechnologies). URL: http://www.nanotechproject.org/index.php?id=44 (accessed 30 November 2006).

Wynne, B. (1992) "Uncertainty and Environmental Learning; Reconceiving Science and Policy in the Preventive Paradigm," Global Environmental Change 3: 111-27.

\section{Authors}

Tee Rogers-Hayden is a Center for Nanotechnology in Society University of California Santa Barbara (CNS-UCSB) Affiliated Research Fellow in the School of Psychology at Cardiff University. She is a Science and Technologies Studies (STS) researcher with a background in analyzing public debates, on GM and nanotechnologies, in New Zealand and in the UK. She is currently undertaking research into stakeholder deliberation and public participation on nanotechnologies in the UK and the US.

Nick Pidgeon is with the School of Psychology at Cardiff University UK. He has current research interests in risk perception and risk communication across a range of technological controversies including GM agriculture, nuclear power, climate change and nanotechnologies. He has also researched deliberative and stakeholder processes for addressing public policy decisions in science and technology. Correspondence: School of Psychology, Cardiff University, Tower Building, Park Place, Cardiff CF10 3AT, UK; e-mail: PidgeonN@Cardiff.ac.uk 